\title{
On the taxonomic recognition of skinks from the Guadeloupe Archipelago (Squamata, Mabuyidae, Mabuya)
}

\author{
S. Blair Hedges ${ }^{1, *}$, Olivier Lorvelec $^{2,3}{ }^{\text {, Nicolas Barré }}{ }^{3}$, Nicolas Vidal ${ }^{4}$, and Claudie Pavis ${ }^{3}$ \\ 'Center for Biodiversity, Temple University (502 SERC), 1925 N. 12th Street, Philadelphia, PA 19122, USA. \\ 2INRA, UMR0985 Écologie et Santé des Écosystèmes, Agrocampus ouest, 35042 Rennes Cedex, France. \\ ${ }^{3} A E V A$, Association pour l'Étude et la protection des Vertébrés et végétaux des petites Antilles, 97170 Petit Bourg, Guadeloupe, France. \\ ${ }^{4}$ ISYEB, UMR7205 MNHN-CNRS-UPMC-EPHE, Muséum National d'Histoire Naturelle, Département Systématique et Evolution, CP30 25 rue Cu- \\ vier 75005 Paris, France. \\ *Corresponding author (sbh@temple.edu)
}

Edited by: Robert W. Henderson. Date of publication: 6 March 2019.

Citation: Hedges SB, Lorvelec O, Barré N, Vidal N, Pavis C. 2019. On the taxonomic recognition of skinks from the Guadeloupe Archipelago (Squamata Mabuyidae, Mabuya). Caribbean Herpetology 64:1-7.

DOI: $10.31611 /$ ch.64

\begin{abstract}
The six species of mabuyid lizards (skinks) of the Guadeloupe Archipelago are Capitellum mariagalantae, Mabuya cochonae, M. desiradae, M. grandisterrae, M. guadeloupae, and M. parviterrae. All are critically endangered and four may be extinct, primarily from predation by introduced mammals. These six species were described in recent years from molecular and morphological analyses. Miralles et al. (2017, Bulletin de la Société Herpétologique de France, 163, 67-84) has challenged the taxonomy, claiming that the six species cannot be diagnosed from each other, and recognized only a single species, Mabuya desiradae. We find that their study contains errors that led them to that incorrect conclusion, including a probable data handling error in the molecular analysis and the use of non-diagnostic morphological characters.
\end{abstract}

Keywords: Caribbean, island, lizard, phylogeny, Mabuya, conservation, systematics.

\section{Introduction}

Skinks of the lizard family Mabuyidae occur throughout the Caribbean region and are especially diverse in the Guadeloupe Archipelago, where six named species occur, all endemic to individual islands: Capitellum mariagalantae, Mabuya cochonae, M. desiradae, M. grandisterrae, M. guadeloupae, and M. parviterrae (Hedges \& Conn 2012; Hedges et al. 2016). They are critically endangered species primarily because of predation by introduced mammals, especially the Small Indian Mongoose, Urva auropunctata. Only two of the species, M. desiradae (from La Désirade) and $M$. parviterrae (from Terre de Bas, Îles de la Petite Terre), have been observed in recent years. The species $M$. parviterrae is particularly threatened, with an estimated 50 individuals surviving primarily in a single stone wall (Hedges et al. 2016). Additional surviving populations of skinks in the Guadeloupe Archipelago, not yet assigned to a species, occur on the small islets of Les Saintes, specifically from Terre-de-Haut and Terre-de-Bas (Angin \& Gomès 2015; Barré et al. 2016).

Before 2012, there was little concern for these lizards from Guadeloupe because they were thought to belong to a single, wide-ranging species, Mabuya mabouya, as concluded by studies of morphological and molecular data (Miralles 2005; Miralles et al. 2009). However, Hedges \& Conn (2012) came to a different conclusion after conducting a comprehensive study utilizing new molecular data, together with a greatly-expanded morphological data set (30 characters) scored from 750 specimens, compared with 311 specimens in the previous work. The Hedges \& Conn (2012) study revealed a hidden diversity of skink species in the Western Hemisphere and especially 
on Caribbean islands. As part of that work, they described five of the six known species in the Guadeloupe Archipelago, with M. parviterrae described later (Hedges et al. 2016).

Recently, Miralles et al. (2017) revisited the taxonomy of skinks in the Guadeloupe Archipelago with new sequence data from seven specimens representing two of the six named species (M. desiradae and M. parviterrae), including three individuals from Les Saintes (two from Terre-de-Haut and one from Terre-de-Bas) that are unassigned to a species. They combined those data with published sequence data (Hedges et al. 2016) from 12 specimens of those species (two from La Désirade and ten from Îles de la Petite Terre), concluding that the molecular evidence supports the recognition of a single species (Mabuya desiradae) from the Guadeloupe Archipelago instead of six species. Oddly, their resulting tree of relevance (Miralles et al. 2017: Fig. 2D) supported the opposite conclusion, showing that the two species formed strongly-supported genetic groups, except for a single individual from La Désirade that was genetically identical to $M$. parviterrae. We consider the latter to be a data-handling error made by those authors (see below). The new morphological data taken by Miralles et al. (2017) were irrelevant because they failed to score characters determined to be diagnostic in previous studies (see below). Here, we examine the study of Miralles et al. (2017), showing that it contains errors and inconsistencies and draws conclusions that are unsupported by their own data.

Most (seven) of the 11 new sequences contributed by Miralles et al. (2017) (their Table 1, in bold) were from a conserved gene, $12 \mathrm{~S}$ rRNA, with only four new cytochrome $b$ sequences. Because our data (Hedges et al. 2016) were from the more relevant cytochrome $b$ gene, we corrected this imbalance by adding new $12 S$ rRNA sequences for our 12 samples in order to have an alignment of 17 individuals for both genes.

\section{Methods}

All methods followed Hedges \& Conn (2012) and Hedges et al. (2016), including the tree analysis methods (maximum likelihood GTR + gamma model and 2000 bootstrap replications, and Bayesian analysis with MCMC chainlength of 50,000,000. The 11 new sequences of 12S rRNA were deposited in Genbank (MK423217-MK423227, MK432848) and added to cytochrome b sequences from Hedges et al. (2016) (Genbank KU587588-KU587599) and 8 sequences contributed by Miralles et al. (2017): Genbank KT351073-074, KT351076-077, KT351079-82. We did not use sequences from several individuals (PT6-PT7, TdB1) in Miralles et al. (2017) for our phylogenetic analysis because they were from the conserved 12S rRNA gene; the relevant variable gene, cytochrome $b$, was not sequenced by those authors in those individuals. Most of the new sequences are of Mabuya parviterrae (SBH 274694-695, 274765-772) from îles de la Petite Terre, Terre de Bas (16.169, -61.121). One (SBH 274696) is from La Désirade, Baie Mahault (16.331, -61.017) and another (SBH 274777) is from La Désirade; Beausejour (16.304, -61.072). See Genbank numbers (Genbank 2019) for complete localities and coordinates. Museum and laboratory voucher abbreviations are KU (University of Kansas, Natural History Museum), MNHN (Muséum National d'Histoire Naturelle, Paris), and SBH (Laboratory of S. Blair Hedges, Temple University); some Genbank accession numbers, coincidentally, begin with "KU" but are so indicated.

\section{Results and Discussion}

The molecular evidence. The only relevant molecular analysis in Miralles et al. (2017) was that of cytochrome b sequences in Guadeloupe skinks, rooted with the closest relative M. dominicana, which was done by those authors (Miralles et al.: Fig. 2D). This is because cytochrome b, and other protein-coding mitochondrial genes, evolve several times faster than $12 \mathrm{~S}$ rRNA, providing the needed variation for closely related species, and sequences of that gene are available for most (16 of the 19) sampled individuals from Guadeloupe, compared with only seven sequenced individuals for $12 \mathrm{~S}$ rRNA. The most relevant analysis of Miralles et al. (2017) shows strong support for the monophyly of skinks from different islets of Guadeloupe, justification for recognition of the species diagnosed by Hedges \& Conn (2012) and Hedges et al. (2016), pertinent here: M. desiradae and M. parviterrae. This is not sur- 
prising because most of the sequences of those two species, used by Miralles et al. (2017), were produced and analyzed in those two earlier studies. Our new tree (Fig. 1) fills in the missing 12S rRNA data and confirms that result. In particular, it shows again the differentiation of skinks from three islets of the Guadeloupe Archipelago and the anomalous specimen "Des2" from the study of Miralles et al. (2017).

This brings us to the conundrum: why Miralles et al. (2017) concluded the opposite of what they demonstrated (their Fig. 2D). They claimed that they were "unable to find any differentiation between the different populations of the islands of Guadeloupe." As noted above, the $12 \mathrm{~S}$ rRNA data they presented (e.g., their Fig. 2C) are not relevant because they are too slow-evolving and there are too few sequences. Although not stated by them, the answer must lie in that one problematic specimen, their "Des2" = "Désirade (a)" in Fig. 2 of Miralles et al. (2017) from La Désirade, which does not group with the other three individuals from that island but instead is genetically identical to the 10 individuals of $M$. parviterrae. Their hypothesis, apparently, is that the two islands are occupied by a single species and therefore the mixing of haplotypes on multiple islands supports that hypothesis.

However, the bulk of evidence rejects that hypothesis. The remaining 15 individuals show complete isolation of three island clades, with no sharing of haplotypes among islands. Secondly, the diagnostic morphological data (Hedges et al. 2016, and see below), coded by nuclear genes, agree with the mitochondrial sequence data in showing monophyletic island clades, differentiated from each other. Thirdly, the islands have not been connected since the Pleistocene or earliest Holocene and are separated by $12 \mathrm{~km}$ (La Désirade and Petite Terre) and $60 \mathrm{~km}$

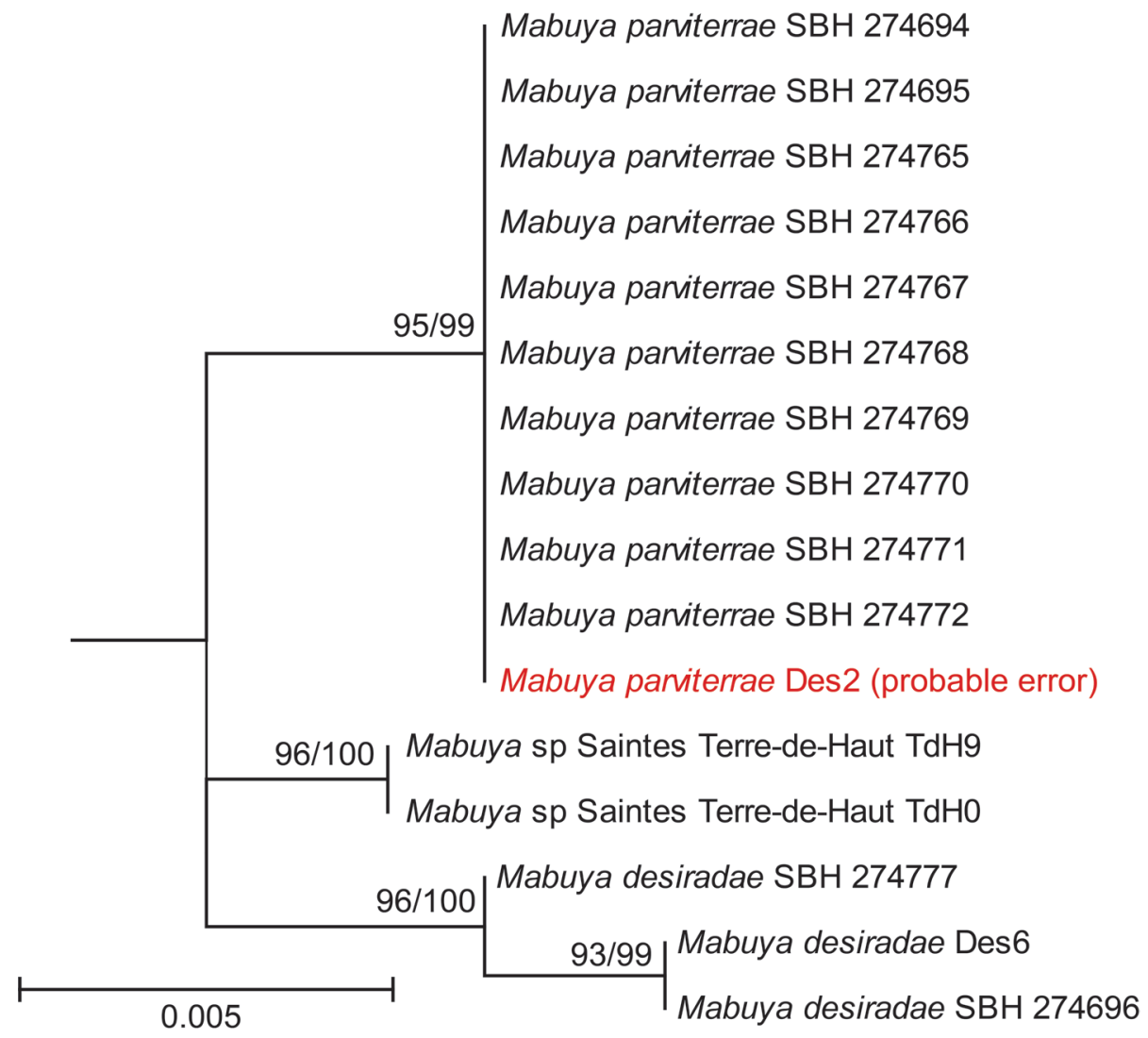

Figure 1. Phylogenetic tree of two species of skinks in the Guadeloupe Archipelago, Mabuya parviterrae and M. desiradae. Two individuals from Les Saintes, unassigned to species, are included. The tree is from a maximum-likelihood analysis of DNA sequences of $12 \mathrm{~S}$ rRNA and cytochrome $b$ (only samples with both genes). A scale bar (sequence divergence) is indicated. The numbers at nodes are bootstrap support values from maximum likelihood (left) and Bayesian (right) analyses. The tree is rooted with Mabuya dominicana (not shown). The sample from Miralles et al. (2017), claimed to be from La Désirade, is considered here to be an error and indicated in red. 
(Petite Terre and Les Saintes) of ocean. Therefore, genetic and morphological differences (Hedges et al. 2016) are what should be expected in these isolated island populations, disagreeing with the conclusions of Miralles et al. (2017). Finally, there are endemic reptile species known from each of these three islands: Anolis (or Ctenonotus) chrysops from Petite Terre, Anolis (or Ctenonotus) desiradei from La Desirade, and Anolis (or Ctenonotus) terraealtae, Sphaerodactylus phyzacinus, and Alsophis sanctonum from Les Saintes.

In other words, we conclude that the finding of genetically identical individuals of skinks on two of these widely separated islands most likely represents a data handling error by Miralles et al. (2017). All other explanations are less likely, including incomplete lineage sorting, a recent dispersal event, or human introduction. Incomplete lineage sorting is unlikely because genetic diversity would be reduced within an island, over the large amount of time involved and small population size on the islands. The high degree of endemism in the amphibians and reptiles of Caribbean islands argues against frequent (e.g., recent) dispersal, and the lizards are rare and difficult to collect in their habitats making human introduction unlikely.

Because individual "Des2" of Miralles et al. (2017) was released after sampling, and because those authors did not score the diagnostic characters that were identified for the two species (Hedges et al. 2016), it is not possible to use alternative data to verify the identity of the specimen sampled, or to resample it genetically. We confirm that it has the expected $12 \mathrm{~S}$ rRNA sequence of $M$. parviterrae as well (Table 1). The specimen itself may have been M. desiradae from La Désirade, but the DNA is of M. parviterrae, most likely because of a laboratory mixup.

In addition to the claim of Miralles et al. (2017) that there is "no differentiation" between separate island populations of skinks in Guadeloupe, which was just discussed and rejected, those authors also claim that the levels of differentiation are low and on the same level as that of a "single population of skink from Dominica" ( $M$. dominicana). However, Miralles et al. (2017) did not provide locality data on the three specimens of M. dominicana that they used. Two individuals (samples "a" and "b") came from Pointe Baptiste in the NE portion of the island, on the east coast (Miralles et al. 2009) whereas the third (sample "c") came from the west coast at Jimmit (Hedges \& Conn 2012). The two localities are $25 \mathrm{~km}$ apart and separated by the main ridge of the island (1400 m). Skinks are not known from the main ridge (Hedges \& Conn 2012) and therefore the populations appear to be geographically isolated, although possibly connected through populations around the coast of the island. Mabuya dominicana currently is assumed to represent a single species, but there have been no phylogeographic studies, and morphologically it shows some scale and pattern variation (Hedges \& Conn 2012).

Of the two possible nodes in the M. dominicana clade, Miralles et al. (2017) therefore used the incorrect node, the one that connects two widely separated localities that are not obviously in genetic contact, instead of the node that connects the two individuals of a "single population of skink from Dominica." If this mistake were corrected, Miralles et al. (2017) would have to conclude that the degree of differentiation among island clades of Guadeloupe skinks is greater than that separating individuals from a single population of skink, which is the opposite of what they concluded.

However, a more relevant "degree of differentiation" comparison, and one used most commonly in the systematic literature, is to compare the amount of genetic difference separating two populations in question with that between recognized species elsewhere. This is the comparison that was done in the description of M. parviterrae (Hedges et al. 2016). Those authors found that the amount of cytochrome b sequence divergence (0.9\%) separating $M$. parviterrae and $M$. desiradae is approximately the same as that separating four species of skinks in the Puerto Rico region (Spondylurus culebrae, S. macleani, S. monitae, and S. sloanii) and corresponding to a time of separation of approximately 500,000 years ago (Hedges \& Conn 2012).

The morphological evidence. No morphological (or molecular) data were presented or discussed by Miralles et al. (2017) for half of the skink species of Guadeloupe (Capitellum mariagalante, Mabuya cochonae, and M. guadeloupae) even though they recommended that those species be considered invalid. This raises the question: on what grounds? Also, no types or other museum specimens were examined for any species. Furthermore, only seven morphological characters were scored and they did not include any of the original characters used to 
diagnose the species.

The fact that none of the seven morphological characters scored by Miralles et al. (2017) were among the diagnostic characters identified in the original descriptions (Hedges \& Conn 2012; Hedges et al. 2016) is surprising. Any two species will always share a large number of characters that are irrelevant to diagnosing a species (e.g., presence of limbs, etc.) so why show a table (Miralles et al. 2017: Table 3) full of such data? Diagnostic characters, those that differ between species, are the relevant ones (Table 1). In an attempt to explain why they ignored the original diagnostic characters of the species, Miralles et al. (2017) claimed—incorrectly—that Hedges \& Conn

Table 1. Diagnostic characters distinguishing two species of skinks in the Guadeloupe Archipelago, Mabuya parviterrae and M. desiradae. Three individuals from Les Saintes, unassigned to species, are included. Sequence data from a more distantly related species, M. dominicana, are shown (Genbank JN227582, JN227561). Museum numbers in bold are holotypes. Morphological data are from Hedges \& Conn (2012) and Hedges et al. (2016); Ds = dorsal scales, Vs = ventral scales. For the molecular data, all parsimony-informative sites are shown and numbered according to the position in the holotype sequence of $M$. parviterrae (Genbank MK423219, KU587592). A dash indicates that a site or character was not sampled. Individual DES2 was reported by Miralles et al. (2017) as coming from Les Désirade, but the sequence is identical to M. parviterrae, suggesting a data handling error (see text).

\begin{tabular}{|c|c|c|c|c|c|c|c|c|c|c|c|c|c|c|c|c|}
\hline \multirow[b]{2}{*}{ Voucher } & \multirow[b]{2}{*}{ Museum No. } & \multicolumn{3}{|c|}{ 12S rRNA } & \multicolumn{9}{|c|}{ Cytochrome B } & \multicolumn{3}{|c|}{ Morphology } \\
\hline & & 367 & 694 & 730 & 354 & 513 & 627 & 648 & 696 & 716 & 747 & 803 & 939 & Ds & Ds+Vs & Palms \\
\hline \multicolumn{17}{|c|}{ Mabuya parviterrae (Petite Terre) } \\
\hline SBH 274765 & MNHN 2015.0059 & A & C & C & G & G & A & $\mathbf{T}$ & A & $\mathbf{T}$ & C & $\mathbf{T}$ & C & 58 & 123 & dark \\
\hline SBH 274766 & MNHN 2015.0060 & A & C & C & G & G & A & $\mathbf{T}$ & A & $\mathbf{T}$ & C & $\mathbf{T}$ & $\mathbf{C}$ & 58 & 126 & dark \\
\hline SBH 274767 & MNHN 2015.0061 & A & C & C & G & G & A & $\mathbf{T}$ & A & $\mathbf{T}$ & C & $\mathbf{T}$ & C & 56 & 123 & dark \\
\hline SBH 274768 & MNHN 2015.0062 & A & C & C & G & G & A & $\mathbf{T}$ & A & $\mathbf{T}$ & C & $\mathbf{T}$ & C & 57 & 124 & dark \\
\hline SBH 274769 & MNHN 2015.0063 & A & C & C & G & G & A & $\mathbf{T}$ & A & $\mathbf{T}$ & C & $\mathbf{T}$ & C & 60 & 126 & dark \\
\hline SBH 274694 & released & A & C & C & G & G & A & $\mathbf{T}$ & A & $\mathbf{T}$ & C & $\mathbf{T}$ & C & - & - & - \\
\hline SBH 274695 & released & A & C & C & G & G & A & $\mathbf{T}$ & A & $\mathbf{T}$ & C & $\mathbf{T}$ & C & - & - & - \\
\hline SBH 274770 & released & A & C & C & G & G & A & $\mathbf{T}$ & A & $\mathbf{T}$ & $\mathrm{C}$ & $\mathbf{T}$ & C & - & - & - \\
\hline SBH 274771 & released & A & C & C & G & G & A & $\mathbf{T}$ & A & $\mathbf{T}$ & $C$ & $\mathbf{T}$ & C & - & - & - \\
\hline SBH 274772 & released & A & C & C & G & G & A & $\mathbf{T}$ & A & $\mathbf{T}$ & C & $\mathbf{T}$ & C & - & - & - \\
\hline DES2 & released & - & C & C & - & G & A & $T$ & A & $T$ & C & $T$ & C & - & - & - \\
\hline PT6 & released & - & C & C & - & - & - & - & - & - & - & - & - & - & - & - \\
\hline PT7 & released & - & C & C & - & - & - & - & - & - & - & - & - & - & - & - \\
\hline SBH photos & released & - & - & - & - & - & - & - & - & - & - & - & - & 58 & 123 & dark \\
\hline
\end{tabular}

\section{Mabuya desiradae (La Désirade)}

\begin{tabular}{|c|c|c|c|c|c|c|c|c|c|c|c|c|c|c|c|c|}
\hline SBH 274777 & MNHN 2015.0065 & $\bar{T}$ & C & $\mathbf{T}$ & A & C & G & C & G & $\bar{T}$ & $\bar{T}$ & $\mathbf{T}$ & C & 61 & 133 & pale \\
\hline SBH 274696 & released & $\mathbf{T}$ & C & $\mathbf{T}$ & A & C & G & C & G & $\mathbf{T}$ & $\mathbf{T}$ & C & $\mathbf{T}$ & - & - & - \\
\hline DES6 & released & - & C & $\mathbf{T}$ & - & C & G & C & G & $\mathbf{T}$ & $\mathbf{T}$ & C & $\mathbf{T}$ & - & - & - \\
\hline SBH 274931 & MNHN 2015.0064 & - & - & - & - & - & - & - & - & - & - & - & - & 63 & 134 & pale \\
\hline- & KU 242045 & - & - & - & - & - & - & - & - & - & - & - & - & 62 & 130 & pale \\
\hline - & KU 242046 & - & - & - & - & - & - & - & - & - & - & - & - & 62 & 132 & pale \\
\hline
\end{tabular}

Mabuya sp. (Les Saintes)

TdH9 released

TdHO released

TdB1 released

\begin{tabular}{|c|c|c|c|c|c|c|c|c|c|c|c|c|c|}
\hline- & $\mathbf{T}$ & $\mathbf{T}$ & - & C & A & $\mathbf{T}$ & A & C & $\mathbf{T}$ & $\mathbf{T}$ & C & - & - \\
\hline - & $\mathbf{T}$ & $\mathbf{T}$ & - & C & A & $\mathbf{T}$ & A & C & $\mathbf{T}$ & $\mathbf{T}$ & C & - & - \\
\hline- & C & $\mathbf{T}$ & - & - & - & - & - & - & - & - & - & - & - \\
\hline
\end{tabular}

\section{Mabuya dominicana (Dominica)}

\begin{tabular}{ll|l|l|l|l|l|l|l|l|l|l|l|l|l}
\cline { 2 - 13 } SBH 268001 & released & A & C & C & A & C & A & A & A & T & T & T & C & - \\
\hline
\end{tabular}


(2012) and Hedges et al. (2016) used only measurements of head scales and contact sutures, "flexible soft tissues sensitive to preservation conditions," and that those authors "exceeded the $0.1 \mathrm{~mm}$ measurement accuracy" of their calipers.

First, reptile head scales are widely considered to be measurable, commonly used in taxonomic research, and not affected by different preservation conditions, especially when treated as proportions (relative to snoutvent length), as is common practice. And even one of the authors (Miralles) making that criticism has used measurements of single scales and sutures, as well as real soft tissue such as eyes, to diagnose some new reptile species (Crottini et al. 2015). Secondly, Hedges \& Conn (2012: p. 12) used calipers with $0.01 \mathrm{~mm}$ accuracy. Lastly, Miralles et al. (2017) did not explain why they ignored the diagnostic characters of Hedges \& Conn (2012) and Hedges et al. (2016) that involved scale counts and color pattern differences, and why they did not score those characters in their newly collected specimens. For example, dorsal and ventral scale counts completely separate $M$. desiradae (130-134) from M. parviterrae (123-126), and Miralles et al. (2017) had the opportunity to confirm or refute those diagnostic characters.

\section{Conclusions}

The study of Miralles et al. (2017) contains errors that led them to an incorrect conclusion. It was not a taxonomic study of current standard because types and other museum specimens were not examined, and published diagnostic characters of the species, including scale counts and pattern differences, were not scored or discussed. When the authors analyzed molecular data, they found differentiated and monophyletic island clades (except for one specimen, likely an error), corroborating earlier work, yet they concluded the opposite. When a "degree of difference" criterion was attempted, the wrong node in the tree was used. The authors dismissed one class of characters (mensural) used in the earlier work while using the same type of characters in their own work. For all of these reasons, Miralles et al. (2017) does not present a challenge to the existing taxonomy of the skinks of the Guadeloupe Archipelago.

Many of our criticisms of Miralles et al. (2017) apply to an earlier study with shared authorship, Pinto-Sanchez et al. (2015), which focused on Central and South American species in the genus Marisora but which pertains to skinks in the Guadeloupe Archipelago. That study also made taxonomic conclusions, rejecting species and genera described by Hedges \& Conn (2012) and earlier researchers, yet types and other museum specimens were not examined and published diagnostic characters were ignored and not discussed. They used a molecular method of species delimitation incorrectly by attempting to delimit species already diagnosed morphologically. They used species labels assigned to specimens by museums without examining the actual specimens, in a group with a volatile taxonomic history (i.e., errors were created by using such labels without verification). In addition, after finding that their phylogeny matched trees in earlier studies and was consistent with the current taxonomy of 16 genera for the Western Hemisphere (Hedges \& Conn 2012), they rejected the entire generic classification because two species were misplaced, rather than reassigning those species to the correct genus, which would have been simpler. For these reasons, we also reject the taxonomic conclusions of Pinto-Sanchez et al. (2015), including their lack of recognition of the genus Capitellum, distributed in the Guadeloupe Archipelago.

As with any study of allopatric populations of organisms, we cannot be sure that the skinks of La Désirade and Petite Terre have reached the species level of differentiation, because that involves information on genetic incompatibility and reproductive isolation, inaccessible for most groups of organisms including this one. Instead, taxonomists use diagnostic differences, together with distributional data, as a proxy for assessing reproductive isolation. In summary, we reject the claim of Miralles et al. (2017) that Mabuya desiradae and M. parviterrae are not diagnosable. They are not only diagnosable but differ in multiple molecular and morphological characters, consistent with typical, non-overlapping, differences among recognized species of reptiles. 


\section{Acknowledgements}

The field work was conducted under the scope of a project to study the conservation of skinks of the French West Indies, hosted by the Association pour l'Étude et la protection des Vertébrés et végétaux des petites Antilles - AEVA (OL, NB, CP), since 2012. We thank the Direction de l'Environnement, de l'Aménagement et du Logement (DEAL) de la Guadeloupe, especially Luc Legendre, for funding, authorization to collect biological material of a protected species, and authorization to transport that material to the USA. We thank managers of the Réserve Naturelle Nationale des îles de la Petite Terre: the Office National des Forêts (ONF), especially the Conservator René Dumont, for authorizations for working and sampling in the reserve, and the Association Titè, i.e., its President Raoul Lebrave and all the rangers for their participation in field work. NV was supported by a grant from the Muséum National d'Histoire Naturelle (MNHN). We thank the staff of the Center for Biodiversity for analytical assistance, in particular Allison Loveless and Kathleen McGrath. We thank Gunther Köhler and an anonymous reviewer for comments on the manuscript. SBH was supported by the Center for Biodiversity, Temple University, and by grants from the U.S. National Science Foundation.

\section{References}

Angin B, Gomès R (2015) First report of a skink population on Les Saintes (Guadeloupe, FWI). Caribbean Herpetology, 52, 1-2.

Barré N, Trillot A, Lorvelec O (2016) Skinks occur on Terre-de-Bas, Les Saintes (Guadeloupe, French West Indies. Caribbean Herpetology, 56, 1-2.

Crottini A, Harris DJ, Miralles A, Glaw F, Jenkins RKB, Randrianantoandro JC, Bauer AM, Vences M (2015) Morphology and molecules reveal two new species of the poorly studied gecko genus Paragehyra (Squamata: Gekkonidae) from Madagascar. Organisms, Diversity \& Evolution, 15, 175-198.

Genbank (2019) Nucleotide: http://www.ncbi.nlm.nih.gov/genbank/. Accessed 11 January 2019. (National Institutes of Health, Bethesda, Maryland).

Hedges SB, Conn CE (2012) A new skink fauna from Caribbean islands (Squamata, Mabuyidae, Mabuyinae). Zootaxa, 3288, 1-244.

Hedges SB, Lorvelec O, Barré N, Berchel J, Diard Combot M, Vidal N, Pavis C (2016) A new species of skink from the Guadeloupe Archipelago (Squamata, Mabuyidae, Mabuya). Caribbean Herpetology, 53, 1-14.

Miralles A (2005) The identity of Lacertus mabouya Lacepede, 1788, with description of a neotype: an approach toward the taxonomy of New World Mabuya. Herpetologica, 61, 46-53.

Miralles A, Gomes R, Angin B, Ibene B (2017) Étude systématique des scinques Mabuya de l'archipel guadloupéen (Squamata, Scincidae). Bulletin de la Société Herpétologique de France, 163, 67-84.

Miralles A, Rivas G, Bonillo C, Schargel WE, Barros T, García-Pérez JE, Barrio-Amoros CL (2009) Molecular systematics of Caribbean skinks of the genus Mabuya (Reptilia, Scincidae), with descriptions of two new species from Venezuela. Zoological Journal of the Linnean Society, 156, 598-616.

Pinto-Sanchez NR, Calderon-Espinosa ML, Miralles A, Crawford AJ, Ramirez-Pinilla MP (2015) Molecular phylogenetics and biogeography of the Neotropical skink genus Mabuya Fitzinger (Squamata: Scincidae) with emphasis on Colombian populations. Molecular Phylogenetics and Evolution, 93, 188-211. 